\title{
Identification of the Specific Spoilage Organism in Farmed Sturgeon (Acipenser baerii) Fillets and Its Associated Quality and Flavour Change during Ice Storage
}

\author{
Zhichao Zhang ${ }^{1,2,+}$, Ruiyun $\mathrm{Wu}^{1,+} \mathbb{1}$, Meng Gui ${ }^{3}$, Zhijie Jiang ${ }^{4}$ and Pinglan Li ${ }^{1, *}$ \\ 1 Beijing Laboratory for Food Quality and Safety, College of Food Science and Nutritional Engineering, \\ China Agricultural University, Beijing 100083, China; zhgio2008@126.com (Z.Z.); wry0814@cau.edu.cn (R.W.) \\ 2 Jiangxi Institute of Food Inspection and Testing, Nanchang 330001, China \\ 3 Beijing Fisheries Research Institute, Beijing 100083, China; guimeng172@126.com \\ 4 NMPA Key Laboratory for Research and Evaluation of Generic Drugs, Beijing Institute for Drug Control, \\ Beijing 102206, China; Jiangzhijie@126.com \\ * Correspondence: lipinglan@cau.edu.cn; Tel.: +86-10-6273-8678 \\ + The authors contributed equally to this work.
}

Citation: Zhang, Z.; Wu, R.; Gui, M.; Jiang, Z; Li, P. Identification of the Specific Spoilage Organism in Farmed Sturgeon (Acipenser baerii) Fillets and Its Associated Quality and Flavour Change during Ice Storage. Foods 2021, 10, 2021. https:// doi.org/10.3390/foods10092021

Academic Editor: Soottawat Benjakul

Received: 14 July 2021

Accepted: 26 August 2021

Published: 28 August 2021

Publisher's Note: MDPI stays neutral with regard to jurisdictional claims in published maps and institutional affiliations.

Copyright: () 2021 by the authors. Licensee MDPI, Basel, Switzerland. This article is an open access article distributed under the terms and conditions of the Creative Commons Attribution (CC BY) license (https:// creativecommons.org/licenses/by/ $4.0 /)$.

\begin{abstract}
Hybrid sturgeon, a popular commercial fish, plays important role in the aquaculture in China, while its spoilage during storage significantly limits the commercial value. In this study, the specific spoilage organisms (SSOs) from ice stored-sturgeon fillet were isolated and identified by analyzing their spoilage related on sensory change, microbial growth, and biochemical properties, including total volatile base nitrogen (TVBN), thiobarbituric acid reactive substances (TBARS), and proteolytic degradation. In addition, the effect of the SSOs on the change of volatile flavor compounds was evaluated by solid phase microextraction (SPME) and gas chromatography-mass spectrometry (GC-MS). The results showed that the Pseudomonas fluorescens, Pseudomonas mandelii, and Shewanella putrefaciens were the main SSOs in the ice stored-sturgeon fillet, and significantly affect the odors by changing the volatile compounds in the sturgeon. Compared with the fresh sturgeon, the appreciable increase of polycyclic aromatic hydrocarbons and tetramethyl-pyrazine might be the spoilage indicators of the sturgeon contaminated by $P$. fluorescens; the appreciable increase of 1-octen-3-ol and (z)-2-penten-1-o might be the potential marker of the sturgeon contaminated by P. mandelii; and the appreciable increase of 1-(3,3-dimethylbicyclo [2.2.1] hept-2-yl)-ethanon and butylated hydroxytoluene were associated with $S$. putrefaciens. This study reveals the relationship between the SSOs and flavor changes in sturgeon fillets, which will contribute to the sturgeon preservation and shelf-life extension.
\end{abstract}

Keywords: sturgeon; Shewanella; Pseudomonas; spoilage; flavour

\section{Introduction}

Sturgeon, one of the oldest fish in the world, is of great biological and economical importance. In 2020, the production of sturgeon in the world was 102 million tons [1]. Sturgeon exhibits high economic and nutritional value due to its great utilization of body components, including its flesh, skin, caviar, and cartilage [2]. The content of essential amino acids and polyunsaturated fatty acids is rich in sturgeon flesh, especially the decosahexaenoic acid (DHA) and eicosapentaenoic acid (EPA) are $~ 12.5 \%$ which is more than in salmon. Sturgeon can be processed into raw fish fillets and smoked fish slices [3,4], which can be found in the current market. However, due to the high water content, rich nutrients, high endogenous enzyme activity, and near neutral $\mathrm{pH}$ value, sturgeon meat products are easy to get spoilage with deteriorated taste and flavor under the joint action of endogenous enzymes and microorganisms during the processing, transportation, and storage [5], which can cause health issue as well as reduce its commercial value. Generally, the initial deterioration of fresh fish quality is caused by autolysis, while subsequently by bacterial 
activity [6] and the microbial growth plays the major role in the fish spoilage. Fresh caught fish is naturally contaminated with various microbes, and only a small portion of microorganisms can survive afterwards. However, just the small portion of microorganisms cause fish spoilage during storage due to their great tolerance to the preservation conditions, and those microorganisms are named as "specific spoilage organisms (SSOs)" [7,8]. Recently, numerous works have accompanied microbiota analysis with the evaluation of quality changes to trace these correspondences [9-11]. However, different microorganisms show different spoilage characteristics, especially in fish. Biogenic amines, such as histamine, putrescine and cadaverine, are considered as indicators of fish spoilage [12]. Therefore, the current research mainly focuses on the analysis of biogenic amines content, but there is no significant difference. Meanwhile, at the beginning of spoilage, proteins, amino acids and other nitrogen-containing substances in the flesh are decomposed under the action of microorganisms. Then some soluble and small molecular compounds are degraded into volatile metabolites, such as ethanol, ketamine, sulfide, indole, aldehydes, esters and lowgrade fatty acids $[13,14]$, which cause the deterioration of the meat texture and color as well as produce the bad odors and toxic compounds $[15,16]$. In seafood products, the ammonia like odor and sour taste were the main problem to maintain the quality during storage. Research indicates that different dominant spoilage bacteria species may affect the fish microbial ecosystem differently, and therefore play different roles to affect the quality. Shewanella putrefaciens is a famous marine fish spoilage bacterium, producing trimethylamine and $\mathrm{H}_{2} \mathrm{~S}$ in the process of metabolism, which brings strong odor $[17,18]$. Photobacterium phosphoreum, associated with acetic acid production, is considered as a spoilage marker in modified atmosphere packaged raw salmon [19]. Production of volatile compounds, such as trimethylamine, ethyl acetate and butanol were believed to play important role in Serratia liqefaciens spoiled cold-smoked salmon [18]. The Carnobacterium maltaromaticum can produce 3-methyl-1-butanal, 2-methyl-1-butanal, 2, 3-butanedione and ethyl acetate, which is also a major spoilage bacterium in fish products [19]. Other typical spoilage bacteria, such as Pseudomonas fragi, Pseudomonas fluorescens, and Shewanella putrefaciens also showed different metabolic characteristics when inoculated into sterile Sebastes melanops muscle [20-24]. In recent years, some literature has reported the relationship between dominant spoilage bacteria from fish and volatile compounds. However, the relationship between the SSOs of sturgeon and their effect on sturgeon products quality change is still missing, especially their role in affecting volatile flavor compounds. At the same time, because sturgeon has a high water content, neutral $\mathrm{pH}$, and rich nutrition, it is very easy to cause microcirculation after death, biological proliferation leads to corruption. Under specific conditions, only part of the microorganisms contained in fish meat participate in the corruption process. Therefore, studying the specific spoilage bacteria and their putrescence ability of fish meat can clarify the corruption process and corruption mode of fish meat, and provide a research basis for the development of safe and efficient preservation technology, reliable shelf-life prediction technology, and freshness indicators.

In this study, the SSOs were isolated and identified from ice stored-aerobic tray packaging sturgeon fillets by analyzing their spoilage potential on sensory change, microbial growth, and biochemical properties, including total volatile base nitrogen (TVBN), thiobarbituric acid reactive substances (TBARS) and proteolytic degradation. Meanwhile, the effect of the SSOs on the change of volatile flavor compounds was evaluated by solid phase microextraction (SPME) and gas chromatography-mass spectrometry (GC-MS).

\section{Materials and Methods}

\subsection{Isolation and Identification of Strains}

The dominant spoilage bacteria in sturgeon fillets stored aerobically on ice were isolated and identified by a combination of culture-dependent and independent (PCRDGGE) methods [25]. Meanwhile, different typical morphological colonies were randomly isolated from plates of Cetrimide Fucidin Cephaloridine (CFC, Hope Biol-Technology Co., Ltd., Qingdao, China) and Iron Agar (black colonies) (IA, Hope Biol-Technology Co., Ltd., 
Qingdao, China), respectively. Five Pseudomonas species (Pseudomonas mandelii (J-2, J-7, J-8, $\mathrm{J}-9)$, Pseudomonas fragi (J-5)), Pseudomonas deceptionensis (J-12), Pseudomonas fluorescens (J-1, J-11, J-13), and Pseudomonas sp. J-10) and 2 Shewanella species (Shewanella putrefaciens (X-1, $\mathrm{X}-2$ ), Shewanella baltica (X-3)) were identified by $16 \mathrm{~S}$ rRNA gene and rpoD gene. Spoilage characteristics of the seven different bacteria were analyzed in the study.

\subsubsection{Total Bacterial DNA Extraction and 16S rDNA V3 Variable Region Amplification}

We aseptically weighed a certain meat sample, cut it with sterilized scissors, and then extracted DNA with bacterial genome rapid extraction kit (Beijing Biomed Technology Development Co., Ltd., Beijing, China).

Nested PCR was used to identify the isolated SSOs according to wang et al. [25] Briefly, the primer 8F: 5'-GGAGAGTTTGATCACTGGCT-3' and 798R: 5'-CCAGGGTATCTAATCCT GTT-3' were used to amplify about 750 bp of $16 \mathrm{~S}$ rDNA sequence in the first PCR reaction; and the primer GC338F: 5'-CGCCCGCCGCGGGGCGGGGCACGGGGGGACTCCTACGGGAGGCAGCAG-3', 518R: 5'-ATTACCGCGGCTGG-3' were used to amplify the V3 region of $16 \mathrm{~S}$ rDNA in the second PCR reaction.

\subsubsection{DGGE Analysis}

Referring to Wang methods [25] with appropriate modification, DGGE analysis of target amplification products in bacterial $16 \mathrm{~S}$ rDNA V3 region was carried out: polyacrylamide gel concentration was 10\% (acrylamide: methylene bisacrylamide 37.5:1), denaturation gradient: $30-60 \%$ (100\% denaturant containing $7 \mathrm{~mol} / \mathrm{L}$ urea and $40 \%$ deionized formamide). Electrophoresis conditions: at $0.5 \times \mathrm{TAE}$ buffer, at $80 \mathrm{~V}$ for $5 \mathrm{~h}$, then at $60 \mathrm{~V}$ for $16 \mathrm{~h}$ at a constant temperature of $60{ }^{\circ} \mathrm{C}$. After electrophoresis, the gel was stained with GelRed nucleic acid dye for $20 \mathrm{~min}$.

After that, under UV irradiation, DGGE strips at different positions were cut off with a

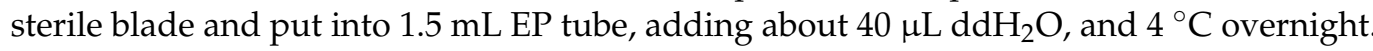
Primers 338F: 5'-ACGGGAGGCAGCAG-3', 518R: 5'-ATTACCGCGGCTGG-3' were used for amplification. The products were purified and sequenced by Biomed Company (Beijing, China). The results were compared and analyzed in NCBI.

\subsection{Sterile Fillet Sample Preparation}

A total of 15 commercially farmed sturgeon (Acipenser baerii) were used in this experiment. Each fish weighed about 7-8 kg and was about 4 years old, was purchased from Sturgeon Farm of Beijing Fisheries Research Institute (Beijing, China). Sterile sturgeon fillets (about $30 \mathrm{~g}$ each fillet) were prepared according to the method described by Huang [26]. After the purchased fresh sturgeon were knocked to death, they were immediately cleaned with $50 \mathrm{~g} / \mathrm{L} \mathrm{Na}_{2} \mathrm{CO}_{3}$ solution to remove the surface mucus and the head, tail, and internal organs. Under the sterile environment, fish were washed $50 \mathrm{~g} / \mathrm{L} \mathrm{Na}_{2} \mathrm{CO}_{3}$ solution and $2 \%$ formalin solution in turn, cut into fish slices (about $30 \mathrm{~g}$ per piece) under the sterile condition, washed thoroughly with sterile water and drained. After culturing and counting, the total number of bacteria in sterilized fish fillets was less than $2 \log (\mathrm{CFU} / \mathrm{g})$. After being made into sterile fillets, the fillets were immediately placed in a sterile container and placed in a super clean bench. Then they were divided randomly into four groups.

All Pseudomonas and Shewanella isolates were grown individually in Nutrient Broth (NB, Hope Biol-Technology Co., Ltd., Qingdao, China) at $30^{\circ} \mathrm{C}$ for $48 \mathrm{~h}$. The inoculation mixture was diluted to approximately $5 \mathrm{Log}\left(\mathrm{CFU} \mathrm{g}^{-1}\right)$ with sterile physiological saline. Sterile sturgeon fillets were soaked in the inoculation mixture for $15 \mathrm{~s}$, and drained. The initial inoculated concentration was 3-4 $\log \left(\mathrm{CFU} \mathrm{g}^{-1}\right)$. The control was performed by inoculating sterile physiological saline into sterile sturgeon fillets. The inoculated fillets were wrapped with a thin polyethylene film and placed in a polystyrene box, then covered with a brittle layer of ice which was replaced every day to maintain a steady temperature. The samples were stored refrigerated at $4 \pm 0.5{ }^{\circ} \mathrm{C}$ for 18 days and analyzed on days $0,3,6$, $9,12,15$, and 18 . 


\subsection{Sensory Analysis}

The sensory was analyzed according to the Quality Index Method (QIM) described by Hovda [27] with some modifications. The sensory panel consists of six trained evaluators. The panelists were required to score the color, brightness, transparency, odor, surface mucus, and texture. The scores were $0-3$, wherein 0 denoted the best quality and 3 denoted the worst quality. The QIM value was the sum of the scores on different quality parameters given by each panelist.

\subsection{Microbiological Analysis}

Minced sturgeon flesh $(10 \mathrm{~g})$ was aseptically transferred into a polyethylene tube containing $90 \mathrm{~mL}$ sterile peptone water $(0.85 \% \mathrm{NaCl}, 0.1 \%$ peptone) and homogenized for $2 \mathrm{~min}$. Serial 10-fold dilutions of the homogenate were carried out in sterile physiological saline. Poured-plate method was used for colony count. The total viable count was incubated on Plate Count Agar (PCA, Hope Biol-Technology Co., Ltd., Qingdao, China) at $30{ }^{\circ} \mathrm{C}$ for 3 days.

\subsection{Biochemical Analysis}

The $\mathrm{pH}$ was measured in 10-fold diluted flesh with a digital $\mathrm{pH}$ meter (PB-10, Satroris, Beijing, China) following the current Determination of $\mathrm{pH}$ value of Chinese national food safety standard (GB 5009.237-2016). Briefly, $1 \mathrm{~g}$ sturgeon meat was added in $5 \mathrm{~mL}$ normal saline. After homogenization, the $\mathrm{pH}$ of the resulting homogenate was determined using a $\mathrm{pH}$ meter. Total volatile basic nitrogen (TVBN) was measured following the current Chinese national food safety standard (GB 5009.228-2016). Thiobarbituric Acid Reactive Substances (TBARS) was measured following the method described by Botsoglou et al. [28] TCA-soluble peptide was measured following the method described by Broekaert et al. [29].

\subsection{Determination of Histamine}

The determination of histamine during storage was carried out according to the method provided in the instructions of the kit (308-16121, China Baobai Biotechnology Co., Ltd.). The mechanism is that histamine in the action of histamine dehydrogenase occurs with a color reaction. According to the protocol supplied instructions, we prepared the histamine in standard solution, mixed and diluted to $50,25,20,10,5,2.5,2$, and $1 \mu \mathrm{g} / \mathrm{mL}$, used to draw the marked curve. Firstly, the fish meat was stirred thoroughly and $24 \mathrm{~mL}$ of $0.1 \mathrm{M}$ EDTA were added. The mixture was heated in a water bath for $20 \mathrm{~min}$. Then the supernatant was obtained by filtration with qualitative filter paper (Hangzhou Special Paper Co., Ltd., Hangzhou, China) and the supernatant was treated with chromogenic agent $(1 \mathrm{~mL})$ and histamine dehydrogenase solution $(0.5 \mathrm{~mL})$. After being kept away from light for $15 \mathrm{~min}$ at $37^{\circ} \mathrm{C}$, the absorbance was measured at $470 \mathrm{~nm}$, and the corresponding histamine content was calculated using the standard curve $\left(Y=0.0096 \mathrm{X}-0.0042, \mathrm{R}^{2}=0.9972, \mathrm{Y}\right.$ represents the histamine concentration $(\mu \mathrm{g} / \mathrm{mL})$ in the sample, and $X$ is the absorbance value at $470 \mathrm{~nm})$.

The proteins of sturgeon flesh were stored for 0 and 18 days, and were extracted according to the method described by Li et al. [30] with some modifications. Sodium dodecyl sulfate-polyacrylamide gel electrophoresis (SDS-PAGE) (Bio-Rad, Hercules, CA, USA) was performed using $10 \%$ separating gel with $5 \%$ stacking gel. The supernatant of total-soluble protein $(10 \mu \mathrm{L})$, water-soluble protein $(16 \mu \mathrm{L})$, and salt-soluble protein $(12 \mu \mathrm{L})$ was loaded onto the gradient polyacrylamide gel made of $5 \%$ stacking gel and $10 \%$ separating gel. Then electrophoresis was performed at a voltage of $80 \mathrm{~V}$ for $20 \mathrm{~min}$, followed by a voltage of $120 \mathrm{~V}$ for $40 \mathrm{~min}$. After separation, gels were stabilized in fixative (50\% ethanol and 10\% acetic acid) for $60 \mathrm{~min}$ and subsequently immersed in stainer $(10 \%$ acetic acid, 50\% ethanol, $0.25 \%$ Coomassie brilliant blue R-250) for $60 \mathrm{~min}$ and destainer ( $25 \%$ ethanol, $8 \%$ acetic acid) for $90 \mathrm{~min}$. 


\subsection{Volatile Compounds Analysis}

The volatile compounds produced by spoilage sturgeon fillets inoculated with Pseudomonas fluorescens, Pseudomonas mandelii, and Shewanella putrefaciens, were analyzed. The non-inoculated sterile sturgeon fillets were prepared as control. The vial system was equilibrated at $60{ }^{\circ} \mathrm{C}$ for $20 \mathrm{~min}$. The solid-phase micro-extraction (SPME) fiber (65 $\mu \mathrm{m}$ PDMS/DVB, Supelco, Bellefonte, PA, USA) was used to absorb volatile compounds at $60{ }^{\circ} \mathrm{C}$ for $30 \mathrm{~min}$, then inserted into the injector port of gas chromatograph in the splitless mode for $2 \mathrm{~min}$ at $250^{\circ} \mathrm{C}$. Volatile compounds were determined by gas chromatograph coupled with mass spectrometry (GC-MS, QP2010 plus, Shimazu, Japan). The oven temperature was held at $40^{\circ} \mathrm{C}$ for $30 \mathrm{~min}$, increased to $120^{\circ} \mathrm{C}$ at the speed of $5^{\circ} \mathrm{C} \mathrm{min}-1$, then ramped at $10{ }^{\circ} \mathrm{C} \mathrm{min}^{-1}$ to $230{ }^{\circ} \mathrm{C}$, and held for $5 \mathrm{~min}$. The scan of masses ranged from 35 to $500 \mathrm{~m} / \mathrm{z}$. The NIST11 library and comparison of mass spectra and linear retention indexes with those of standards injected in the same conditions were used to identify the volatile compounds. The relative content of volatile compounds was determined with area normalization method. The GC conditions were as follows: the initial temperature of the column incubator was $40{ }^{\circ} \mathrm{C}$, the temperature of the injection port was $250{ }^{\circ} \mathrm{C}$, no split injection, the flow rate of carrier gas $(\mathrm{He})$ was $1 \mathrm{~mL} / \mathrm{min}$, the temperature rising program of the column incubator was $40^{\circ} \mathrm{C}$ for $30 \mathrm{~min}, 5{ }^{\circ} \mathrm{C} / \mathrm{min}$ for $120^{\circ} \mathrm{C}, 10^{\circ} \mathrm{C} / \mathrm{min}$ for $230{ }^{\circ} \mathrm{C}$ for $5 \mathrm{~min}$. MS conditions: the temperature of ion source was $200^{\circ} \mathrm{C}$, the temperature of transmission line was $250^{\circ} \mathrm{C}$, the signal was collected in full scan mode, and the scanning range was $35-500 \mathrm{~m} / \mathrm{z}$.

\subsection{Statistical Analysis}

All experiments were conducted in triplicate and results were expressed as mean \pm standard deviation. Principal component analysis (PCA) was employed to visualize differences in multiple parameters on the average data of samples among groups. Comparisons of multiple groups were analyzed by one-way analysis of variance (ANOVA) with Duncan's multiple range test using SPSS 22.0 (SPSS Inc., Chicago, IL, USA) software (significance was defined at $p<0.05$ ).

\section{Results and Discussion}

\subsection{Bacterial Strains}

In general, the bands at different positions in the DGGE map represent different microbial species, and brighter bands indicates greater number of individual bacteria. It can be seen from Figure 1A that during the ice storage process, with the increase of storage time, more bands can be detected by DGGE, and the brightness of the bands at the same position changed, which indicates that during the storage process, the microbial community structure changed dynamically over time. The dominant bacterial species during different storage periods is different.

In order to further clarify the relationship of microbial community structure in fish meat with different storage time, an unweighted pair group method with arithmetical means (UPGMA) method was used to construct the DGGE map. The results are as shown in Figure 1B: according to the similarity of bacterial communities, the flora at $0,3,6$, and 8 days are grouped into one cluster, and that on day $10,12,14$, and 16 are in a separate cluster. During the storage process, microorganisms need a period of adaptation to the new environment, so the flora changes little during the early stage of storage, and the similarity is greater than $80 \%$ among the samples collected at 0,3 , and 6 days; with the increase of storage time, the microorganisms in fish continue to grow and the dominant spoilage bacteria, which causes the fluctuation of the microbial community structure, among which the flora on the eighth day and days 0,3 , and 6 is more than $80 \%$, the similarity was only $50 \%$, but in the subsequent storage stage, the bacterial community structure gradually tended to be stable, and the similarity between the 10th day and the 12 th day was $84 \%$, and the similarity between the 14 th day and the 16th day was as high as $92 \%$. 
(A)

CK Od 3d 6d 8d 10d 12d 14d 16d

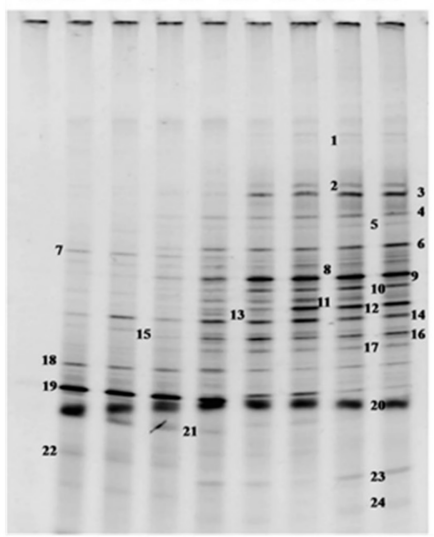

(B)

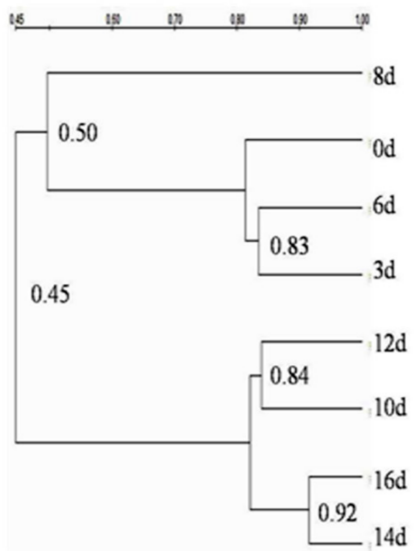

(C)

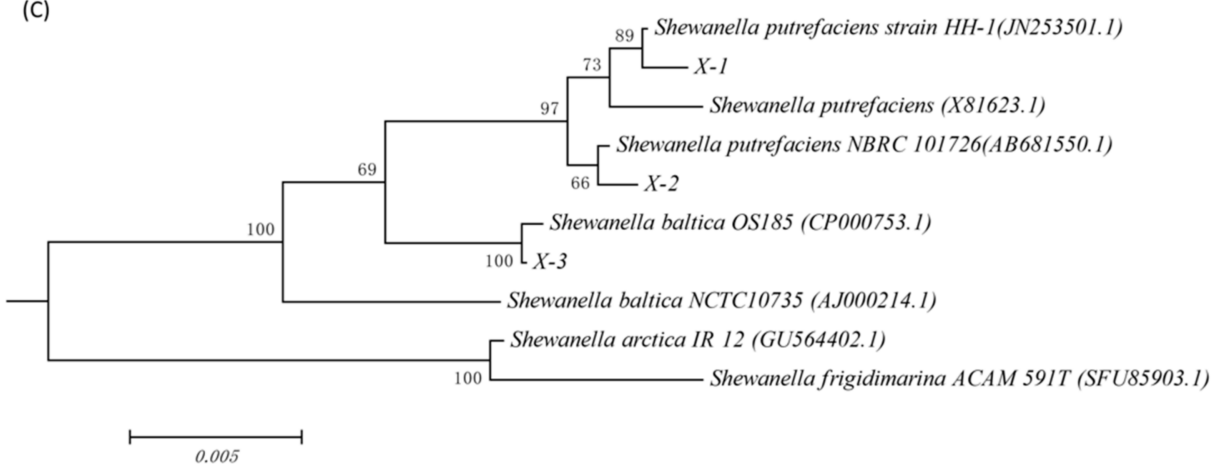

(D)

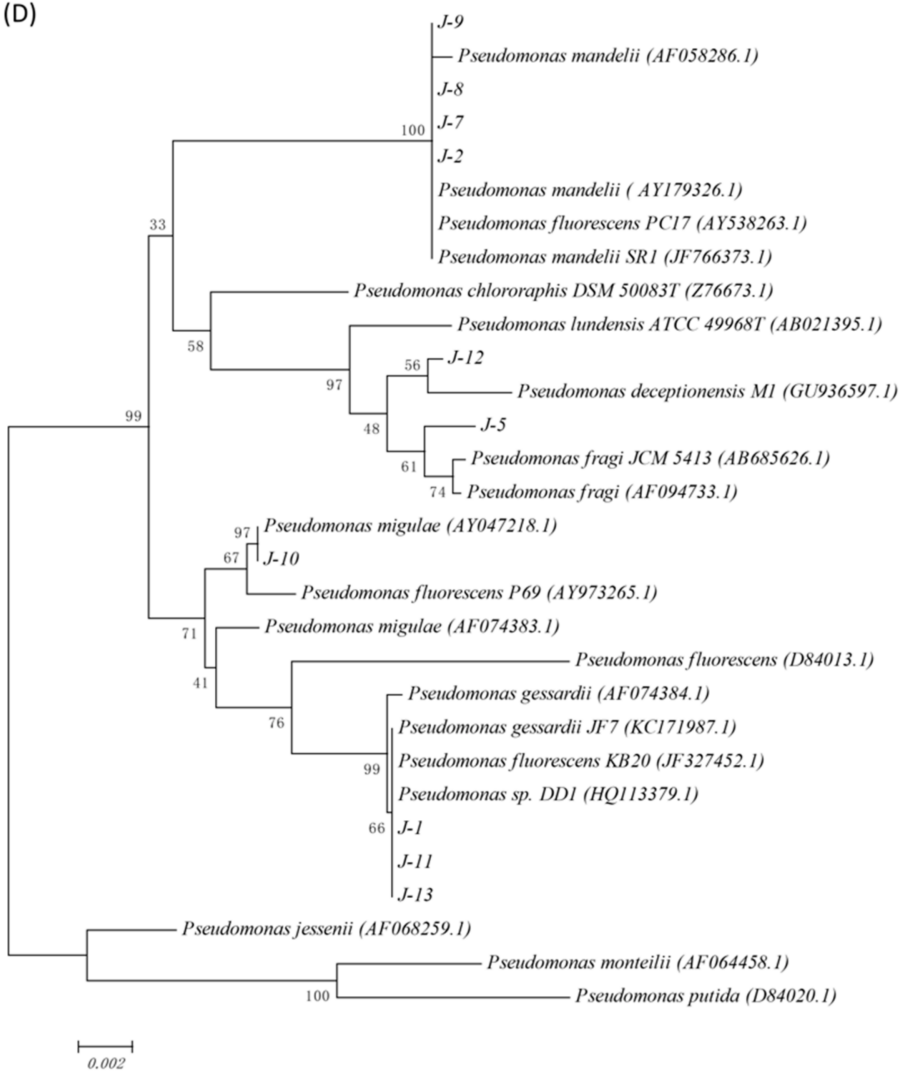

Figure 1. Analysis of DGGE Atlas. DGGE profile of bacteria from sturgeon stored aerobically on ice (A). Cluster analysis of DGGE bacteria profile (B). Phylogenetic tree of the 16S rRNA gene of Shewanella sp. isolated from sturgeon fillets (C). Phylogenetic tree of the 16S rRNA gene of Pseudomnas sp. isolated from sturgeon fillets (D). 
The results of bacteria identification are shown in Table 1. According to DGGE patterns (Figure 1A) and 16S rRNA sequencing analysis (Figure 1C,D), the dominant bacteria in fresh sturgeon were Pseudomonas sp. (bands 7, 14, 18), Shewanella sp. (bands 20), Acinetobacter sp. (bands 19) and Escherichia sp. (bands 22). With the increase of storage time, the brightness of bands $3,4,6,9,10,12$, and 16 increased, indicating that the dominant position of Acinetobacter sp. in microbial flora gradually lost, while the Shewanella sp., Pseudomonas sp., and other microorganisms gradually became dominant bacteria during the late storage period [31]. Shewanella sp. and Pseudomonas sp. are psychrophilic bacteria and can grow at $0^{\circ} \mathrm{C}$. Pseudomonas sp. grows rapidly under aerobic conditions and has strong protein decomposition ability; Shewanella sp. can reduce trimethylamine oxide, producing hydrogen sulfide that can react with pigment in meat tissue, resulting in fish discoloration and produced rancid smell [32].

Table 1. 16S rDNA sequence similarities to closest relatives of DNA recovered from DGGE banks.

\begin{tabular}{cccc}
\hline Number & Most Similar Strain & Login Number & Similarity \\
\hline 1 & Shewanella sp. B157 & FN295752.1 & $95 \%$ \\
2 & Pseudomonas sp. 01WB03.2-36 & FM161452.1 & $96 \%$ \\
3 & Uncultured bacterium clone C16 & AM411553.1 & $95 \%$ \\
4 & Shewanella baltica strain SS3 & JX032783.1 & $96 \%$ \\
5 & Shewanella baltica strain ST5 & JX032790.1 & $97 \%$ \\
6 & Shewanella baltica OS678 & CP002383.1 & $97 \%$ \\
7 & Pseudomonas fluorescens strain M2 & GU947867.1 & $97 \%$ \\
8 & Pseudomonas sp. MFY222 & AY331375.1 & $99 \%$ \\
9 & Pseudomonas sp. R-45822 & FR775122.1 & $100 \%$ \\
10 & Pseudomonas fluorescens & EF408245.1 & $100 \%$ \\
11 & Pseudomonas sp. CB10 & EU482914.1 & $99 \%$ \\
12 & Pseudomonas sp. MDT2-39-4 & JX949559.1 & $99 \%$ \\
13 & Uncultured bacterium clone 07MIC062 & JF340783.1 & $99 \%$ \\
14 & Pseudomonas sp. 01WB02.2-10 & FM161381.1 & $95 \%$ \\
15 & Staphylococcus warneri strain E3b & AY126243.1 & $98 \%$ \\
16 & Bacterium het-w-28 & KC810293.1 & $99 \%$ \\
17 & Pseudomonas sp. CB10 & EU482914.1 & $98 \%$ \\
18 & Pseudomonas sp. IGS61 & JN680232.1 & $99 \%$ \\
19 & Acinetobacter sp. EAXY14 & KC129073.1 & $99 \%$ \\
20 & Shewanella sp. B157 & FN295752.1 & $96 \%$ \\
21 & Microbulbifer maritimus strain MTM147 & HQ705770.1 & $93 \%$ \\
22 & Uncultured Escherichia sp. N5 & AM712054.1 & $98 \%$ \\
23 & Gamma proteobacterium BAL382 & KC140316.1 & $97 \%$ \\
24 & Alteromonadales bacterium HD-I-03-6 & AM931110.1 & $97 \%$ \\
\hline & & &
\end{tabular}

\subsection{Microbiological Analysis}

The results of the total viable counts of different bacteria groups are shown in Figure 2A. The initial count of the control was $1.33 \pm 0.47 \mathrm{Log}\left(\mathrm{CFU} \mathrm{g}^{-1}\right)$, and increased to $3.35 \pm 0.05 \mathrm{Log}\left(\mathrm{CFU} \mathrm{g}{ }^{-1}\right)$ at the end of storage, which showed significant lower values than that of inoculated groups. The initial counts of different inoculated samples were approximately $4 \mathrm{Log}$ (CFU $\mathrm{g}^{-1}$ ) as expected. Pseudomonas fluorescens and Pseudomonas mandelii grew fast after a decline within the initial 3 days. The count was $7.15 \pm 0.01$ and $7.29 \pm 0.05 \log \left(\mathrm{CFU} \mathrm{g}{ }^{-1}\right)$, respectively, at day 12. Meanwhile, Shewanella putrefaciens began to grow rapidly after the sample stored for 12 days. The count reach $8.24 \pm 0.03 \mathrm{Log}$ $\left(\mathrm{CFU} \mathrm{\textrm {g } ^ { - 1 }}\right.$ ), and showed no significant difference from that of Pseudomonas fluorescens group and Pseudomonas mandelii group at the end of storage $(p<0.05)$. The other three bacteria grew at a slow rate, and showed a significant difference compared to others at the later period of storage. Generally speaking, the microorganisms contained in fish from freshwater waters mainly included Pseudomonas and a wide variety of $\mathrm{G}^{+}$bacteria. Reynisson et al. [33] studied the flora structure of North Atlantic cod under the conditions of $0{ }^{\circ} \mathrm{C}$ and micro freezing storage $\left(-2\right.$ and $\left.-3.6{ }^{\circ} \mathrm{C}\right)$. The results showed that Pseudomonas was 
the dominant bacteria for fish meat corruption after storage at $0{ }^{\circ} \mathrm{C}$. Li et al. [34] also made a similar study and compared the bacterial composition of fresh carp slices and thawed carp slices after 4 weeks of freezing at $4{ }^{\circ} \mathrm{C}$. It was found that the dominant bacteria in the spoilage of the two groups were Pseudomonas. It is consistent with our results.

(A)

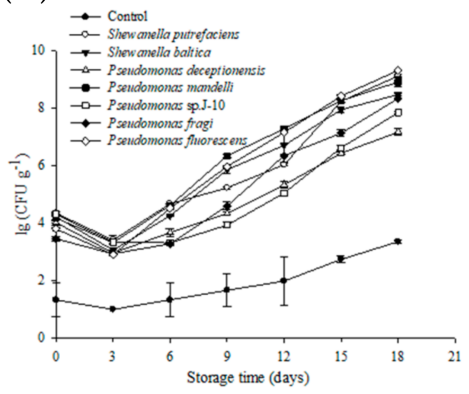

(D)

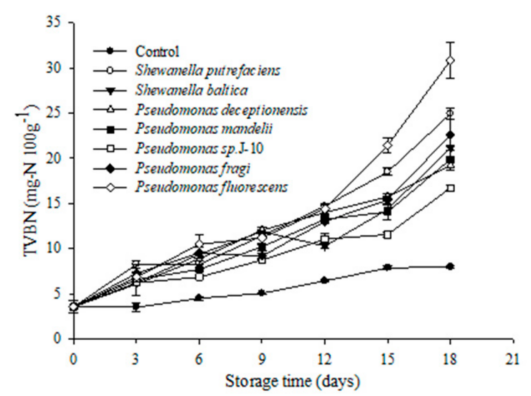

(F)

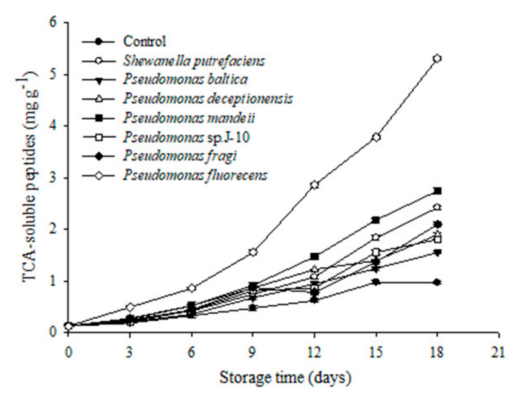

(B)

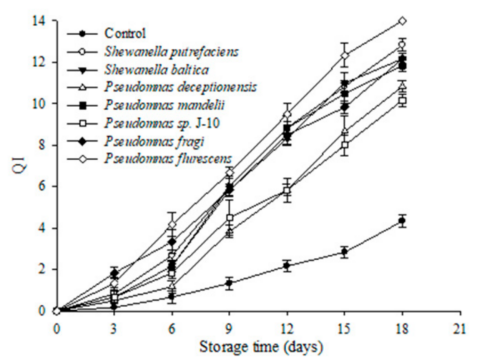

(E)
(C)

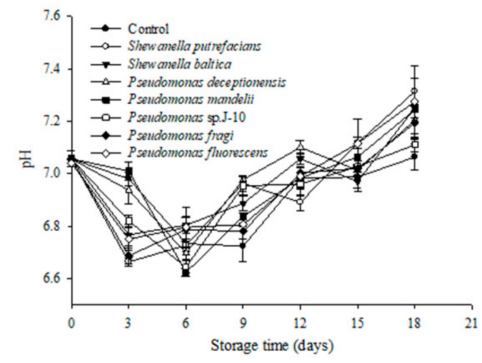

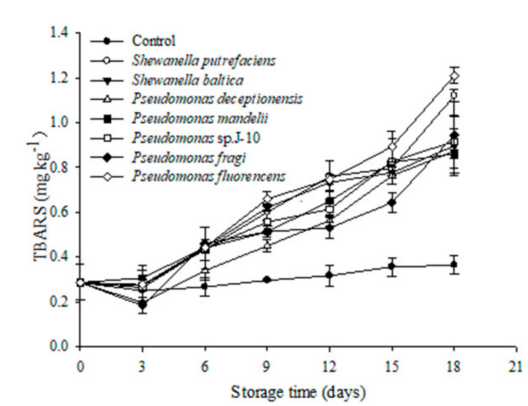

$(\mathrm{G})$

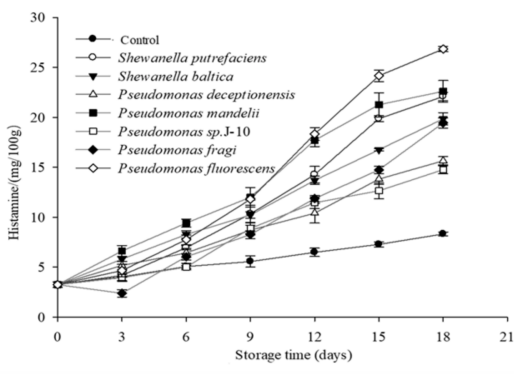

Figure 2. Growth of total bacteria (A), sensory $(\mathbf{B}), \mathrm{pH}(\mathbf{C})$, total volatile base nitrogen (TVBN) production (D), thiobarbituric acid reactive substances (TBARS) (E), TCA-soluble peptides (F), and histamine (G) analysis of sturgeon fillets inoculated with different bacterial groups stored aerobically on ice.

\subsection{Sensory Analysis}

Sensory characteristics of different inoculated sturgeon fillets stored aerobically on ice were analyzed. As is shown in Figure 2B, the control was not considered to be spoiled throughout the 18-day incubation period. Pseudomonas fluorescens inoculated group and Pseudomonas mandelii inoculated group reached the end of shelf life at day 12, and the corresponding QI values were: $9.50 \pm 0.50$ and $8.83 \pm 0.58$, respectively. The samples of Shewanella putrefaciens inoculated group, Shewanella baltica inoculated group, and Pseudomonas fragi inoculated group reached sensory rejection point after 15 days. However, samples of the two other bacterial groups began to deteriorate at day 18. Similar studies have found that modified atmosphere packaged dehydrated pickled cod (Gadidae) can produce dark brown mucus under the action of microorganisms [35], while the meat of sterile bighead carp back connected to Pseudomonas sp. and Shewanella sp. is light green 
and light yellow respectively at the later stage of refrigeration [36]. Similar to our results, it shows that microorganisms are the main factor causing fish meat discoloration.

\subsection{Biochemical Analysis}

The initial pH value of sterile sturgeon fillets was $7.06 \pm 0.03$ (Figure 2C). Overall, all samples showed a trend of $\mathrm{pH}$ increase after a slight decreasing at day 6. This is mainly because after the death of live fish, ATP, phosphocreatine and other substances decompose to produce acidic substances such as phosphoric acid. At the same time, glycogen metabolism produces lactic acid, which reduces the $\mathrm{pH}$ in fish meat. However, with the increase of storage time, endogenous enzymes and surface microorganisms decompose nitrogen-containing compounds such as protein, producing more alkaline substances, resulting in the increase of $\mathrm{pH}[31,37]$. However, the $\mathrm{pH}$ of each experimental group basically fluctuated due to the low ice storage temperature, the slow decline of fish freshness, the insufficient production of acidic substances metabolized by the body, and the accumulation of alkaline substances. So, the of $\mathrm{pH}$ value of Pseudomonas fluorescens group and Shewanella putrefaciens group was higher than that of other bacteria groups at the end of storage, which was $7.35 \pm 0.02$ and $7.31 \pm 0.05$, respectively. Similar studies found that the $\mathrm{pH}$ of grass carp fillets also decreased first and then increased at $-3{ }^{\circ} \mathrm{C}$ and $0{ }^{\circ} \mathrm{C}[31]$, which is consistent with our research results.

Although the TVBN production of different bacteria groups increased slowly at the early period of storage, it was significantly higher than that of the control during storage (Figure 2D). Pseudomonas fluorescens group, Shewanella putrefaciens group, and Shewanella baltica group produced a large amount of TVBN rapidly after being stored for 12 days. Meanwhile, Pseudomonas fluorescens group had the maximum production rate of TVBN, which showed a significant difference compared to other groups, and reached $30.80 \pm 1.98 \mathrm{mg}-\mathrm{N} 100 \mathrm{~g}^{-1}$ at the end of storage. The TVBN value of the four other bacterial groups also increased dramatically after being stored for 15 days.

The TBARS value has been widely used to describe the degree of lipid oxidation. As is shown in Figure 2E, the TBARS value of the control did not change significantly as the storage time extended. Meanwhile, TBARS values of Pseudomonas fluorescens group, and Shewanella putrefaciens group were higher than other bacteria groups at the end of storage, reaching $1.21 \pm 0.03$ and $1.12 \pm 0.03 \mathrm{mg} \mathrm{MDA} \mathrm{kg}^{-1}$, respectively. The TBARS value of Pseudomonas mandelii group was $0.86 \pm 0.02 \mathrm{mg} \mathrm{MDA} \mathrm{kg}^{-1}$, which was the minimum value among all bacteria groups at day18.

Changes of TCA-soluble peptides of different bacteria groups are shown in Figure $2 \mathrm{~F}$. The TCA-soluble peptides production of all bacteria groups increased with storage time extended. The TCA-soluble peptides content of Pseudomonas fluorescens group and Pseudomonas mandelii group increased rapidly after being stored for 9 days, and the similar phenomenon was also found in Shewanella putrefaciens group and Pseudomonas fragi group. Pseudomonas fluorescens inoculated group showed the highest amount of TCA-soluble peptides.

Spoilage characteristics of Pseudomonas mandelii were rarely studied. The samples inoculated with Pseudomonas mandelii also spoiled very quickly and the proteolytic activity was stronger than other inoculated bacteria except Pseudomonas fluorescens, though its TVBN and TBARS values were not high. Pseudomonas fragi has also been identified as the dominating species in meat [38]. Although sensory, microbiological, and some biochemical indexes increased fast in the end of storage in Pseudomonas fragi inoculated samples, these values indicated that the spoilage potential of Pseudomonas fragi did not stand out when compared with other inoculated species in this study. Pseudomonas deceptionensis and Pseudomonas sp. J-10 was found to have the weakest spoilage potential on sturgeon fillets: the dominance of Pseudomonas species depends partly on its ability to metabolize glucose, creatine, and creatinine [39]. Therefore, Pseudomonas species such as Pseudomonas fluorescens that can utilize proteins as its major nutrient sources to grow fast will likely become the dominant species. However, the proteolytic activity of Shewanella putrefaciens was not prominent, but it grew fast. It is possible that Shewanella putrefaciens feed on the proteolytic 
molecules produced by other bacterial species. As for Shewanella baltica, biochemical analysis has shown that the spoilage potential was moderate, though it grew at a fast rate as well as Shewanella putrefaciens. It was found that Shewanella species could produce off-odor compounds, such as $\mathrm{H}_{2} \mathrm{~S}$, which can react with muscle pigments, and result in a green discoloration [40].

\subsection{Changes of Histamine}

The changes of histamine content of the tray packed sturgeon inoculated with different strains during ice storage are shown in Figure $2 \mathrm{G}$ the histamine content of the fish in each experimental group showed an upward trend during storage. In the early stage of storage, histamine production was less. On the 9th day, the histamine content of fish in each treatment group was significantly different from that in the blank control group. This was mainly due to the small number of microorganisms, less histidine decarboxylase production and slow change of histamine content. However, with the gradual adaptation of microorganisms to the storage environment, microbial growth and metabolism were vigorous. The increase of histamine content in each experimental group was accelerated. After 9 days of storage, the histamine content of Pseudomonas fluorescens group and Pseudomonas mandelii group increased significantly. On the 15th day, the histamine content of Pseudomonas fluorescens group was significantly different from other experimental groups, reaching $24.170 \pm 58 \mathrm{mg} / 100 \mathrm{~g}$, while the histamine content in Pseudomonas deceptionensis group and Pseudomonas sp. J-10 group increased slowly during storage, and reached $15.650 \pm 0.41 \mathrm{mg} / 100 \mathrm{~g}, 14.76 \pm 0.39 \mathrm{mg} / 100 \mathrm{~g}$. This indicated that the ability of different microorganisms to promote histamine production in fish was different, among which Pseudomonas fluorescens was the strongest and Pseudomonas sp. J-10 was the weakest.

During the storage of fish, the free histidine is decomposed by histidine decarboxylase to produce histamine under the joint action of endogenous enzymes and microorganisms. Among many biogenic amines, histamine has the greatest impact on human health. Histamine poisoning caused by eating aquatic products occurs from time to time, so it has become an important index to evaluate the freshness of aquatic products [17]. Both Pseudomonas sp. and Shewanella sp. inoculated in this experiment were psychrophilic bacteria, and the activity of histidine decarboxylase was also inhibited due to the low temperature of ice storage, so the histamine content of each experimental group was still lower than the specified limit even after complete spoilage. However, the overall results still reflected the difference of histamine content among the experimental groups.

\subsection{Proteolytic Degradation Analyzed by SDS-PAGE}

The proteolytic degradation of different bacterial groups after being stored for 18 days was analyzed by SDS-PAGE. Twenty to thirty visual bands of total soluble protein were shown in Figure 3A, and the molecular weight ranged from $0 \mathrm{kDa}$ to $230 \mathrm{kDa}$. No significant difference was observed among some main proteins of different bacteria inoculated groups such as myosin heavy chain (MHC, $230 \mathrm{kDa}), \alpha$-actinin $(100 \mathrm{kDa})$, actin (43 kDa), and tropomyosin $(35 \mathrm{kDa})$. However, there were still different characteristics of the total soluble proteins among the different bacteria inoculated groups. The intensity of the bands with molecular weight of approximately 33, 25, 17, 15, and $10 \mathrm{kDa}$ decreased Shewanella baltica group, Pseudomonas fluorescens group, and Pseudomonas mandelii group. The proteins of $15 \mathrm{kDa}$ and $25 \mathrm{kDa}$ were also degraded by Shewanella putrefaciens, Pseudomonas deceptionensis, and Pseudomonas fragi. Meanwhile, the intensity of the bands with molecular weight of approximately $22 \mathrm{kDa}$ and $50 \mathrm{kDa}$ in Pseudomonas fluorescens and Pseudomonas mandeii groups were higher than that of other bacteria groups. This may be the intermediate or oligomer of small protein molecules formed after protein degradation. Interestingly, compared with the total soluble proteins of other groups, a new protein band with the molecular weight less than $10 \mathrm{kDa}$ was observed only in Shewanella species inoculated groups. 
(A)

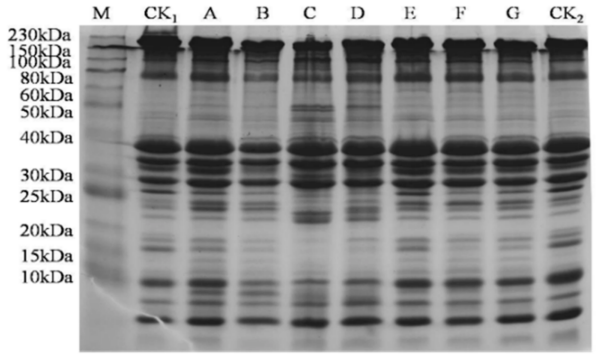

(B)
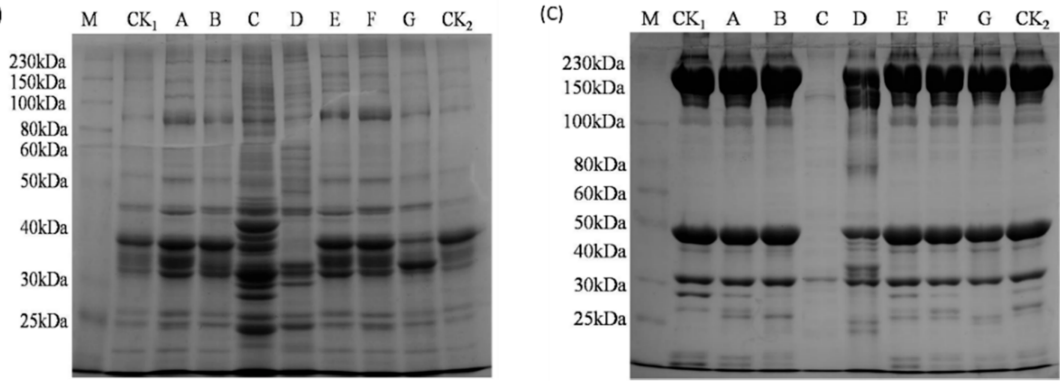

Figure 3. SDS-PAGE analysis of total soluble protein (A), water soluble protein (B), and salt soluble protein $(\mathbf{C})$ of sturgeon fillets inoculated with different bacterial groups and stored aerobically on ice for $18 \mathrm{~d}$. M, protein marker; CK1, control (stored for $0 \mathrm{~d}$ ); A, Shewanella putrefaciens; B, Shewanella baltica; C, Pseudomonas fluorescens; D, Pseudomonas mandelii; E, Pseudomonas sp. J-10; F, Pseudomonas fragi; G, Pseudomonas deceptionensis; CK2, control (stored for $18 \mathrm{~d}$ ).

Changes of water-soluble proteins and salt-soluble proteins of different bacterial groups are shown in Figure 3B and Figure 3C, respectively. The bands of water-soluble proteins had the largest increase while salt-soluble proteins with similar molecular weight almost disappeared in the Pseudomonas fluorescens group. Meanwhile, as is shown in Figure 3B, the intensity of bands with the molecular weight of approximately $90 \mathrm{kDa}$ became higher in different bacterial groups when compared with the control; the intensity of bands in approximately $40 \mathrm{kDa}$ had a slight decrease in Pseudomonas fluorescens group and Pseudomonas deceptionensis group, while the proteins with similar molecular weight disappeared in Pseudomonas mandelli group.

MHC and actin degradation by Pseudomonas mandelli was observed in Figure 3C. An increase of intensity in bands with the molecular weight of approximately $25-40 \mathrm{kDa}$ and 80-100 kDa was found in Pseudomonas mandelli group. As for other bacteria inoculated groups, proteins with molecular weight of $25 \mathrm{kDa}$ to $30 \mathrm{kDa}$ showed difference.

\subsection{Effects of Specific Spoilage Bacteria on Volatile Flavor Compounds of Sturgeon} 3.7.1. Volatile Compounds Analysis

Pseudomonas fluorescens, Pseudomonas mandelii, and Shewanella putrefaciens were considered as strong spoilers based on the basic characteristics of spoilage potential. Volatile compounds produced by these species were further analyzed to find out the possible off-odor contributors. The aldehydes likely come from polyunsaturated fatty acid or amino acid catabolism, and considered as the typical flavor compounds in fresh fish [41]. Volatile compounds were used to analyze the characteristics of spoilage potential of those three bacterial species. Changes of volatile compounds of spoiled samples stored for 15 days are shown in Table S1. The GC-MS spectra of different inoculated samples were determined as shown in the Figure $4 \mathrm{~A}-\mathrm{D}$, according to the peak time and retention time, 35 compounds with the highest content were determined, which included 8 aldehydes, 3 ketones, 1 acid, 1 ester, 5 alcohols, 13 hydrocarbons, and 4 other organic compounds. Changes of volatile compounds of spoiled samples stored for 15 days and peak numbers corresponded to volatiles compounds are shown in the Table S1. The relative contents of aldehydes, al- 
cohols, and hydrocarbons varied greatly among different inoculated samples. To better visualize, a heat-map of the 35 compounds was constructed for different samples at different periods (Figure 4E). Each row represents a separate volatile substance, and each column represents the group used for analysis. In addition, different colors indicated the relative abundance of volatile species, in which high abundance were depicted in red, and conversely, low-abundant were marked in green.

The results show that in all fish samples, hexanal, octanal, nonanal, decanal, dodecanal, hexanol, and ethyl hexanoate content decreased. A corresponding decrease of most of the aldehydes was also found in all spoiled samples in this study when compared with the control. An increasing trend of 2-undecanone, 6, 10-dimethylundeca-5, 9-undecadien-2-one, and 1,3-dichloro-benzene was shown in the spoiled samples, which implied that these compounds might be responsible for off-odors in spoiled sturgeon fillets. Some polycyclic aromatic hydrocarbons and tetramethyl-pyrazine might be the spoilage indicators of the samples inoculated with Pseudomonas fluorescens, polycyclic aromatic hydrocarbons were the off-odor contributors in fish previously. Pyrazine compounds were considered as the empyreumatic-odors source, and were possible to be produced by the condensation reactions between amino acid (ammonia) and dicarbonyl compounds or Maillard reaction. 1-(3, 3-dimethylbicyclo [2.2.1] hept-2-yl)-ethanon and ethyl hexanoate were the specific volatile compounds produced in Shewanella putrefaciens inoculated group, which might be the spoilage markers of this species. An increase of antioxidant BHT was also observed in Shewanella putrefaciens inoculated group. This compound was also found in spoiled salmon inoculated with Photobacterium phosphoreum [42]. Miller et al. [24] found that sterile Sebastes melanops inoculated with Pseudomonas fluorescens or Shewanella putrefaciens produced several sulfur-containing compounds (methyl mercaptan and dimethyl disulfide) and trimetylamine which were not detected in this study. This is likely due to the difference in the type of fish fillets and different experimental procedures. 1-octen-3-ol and (z)-2penten-1-o increased significantly in Pseudomonas mandelii inoculated group, and this was different from other bacteria inoculated groups. This result implied that the spoilage characteristics of Pseudomonas mandelii might relate to unsaturated alcohols, which were considered to originate from oxidation of unsaturated fatty acids [43,44]. Similarly, previous studies used 1-octen-3-ol and (z)-2-penten-1-o as the potential markers for spoilage of other aquatic products $[45,46]$.

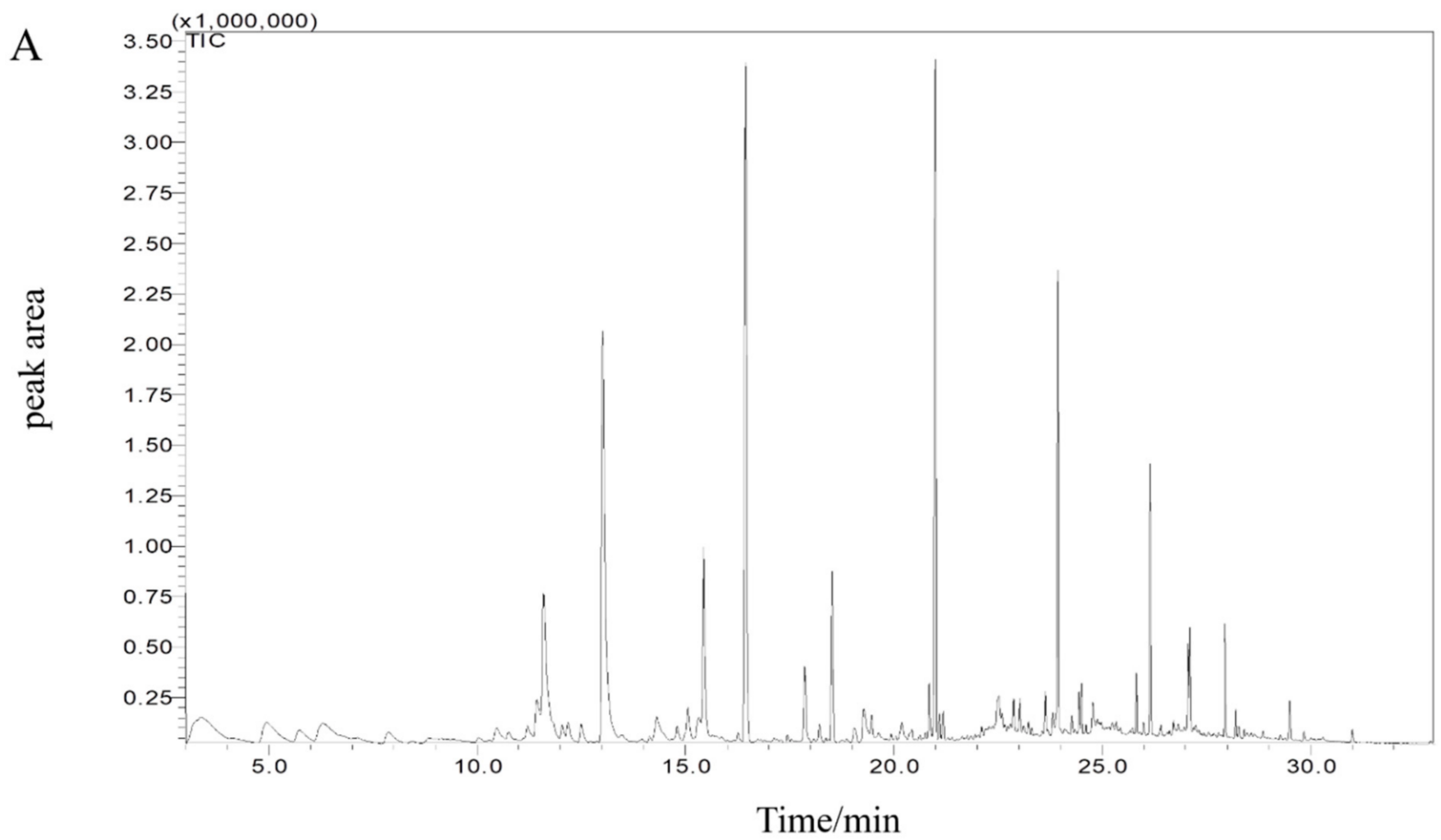

Figure 4. Cont. 


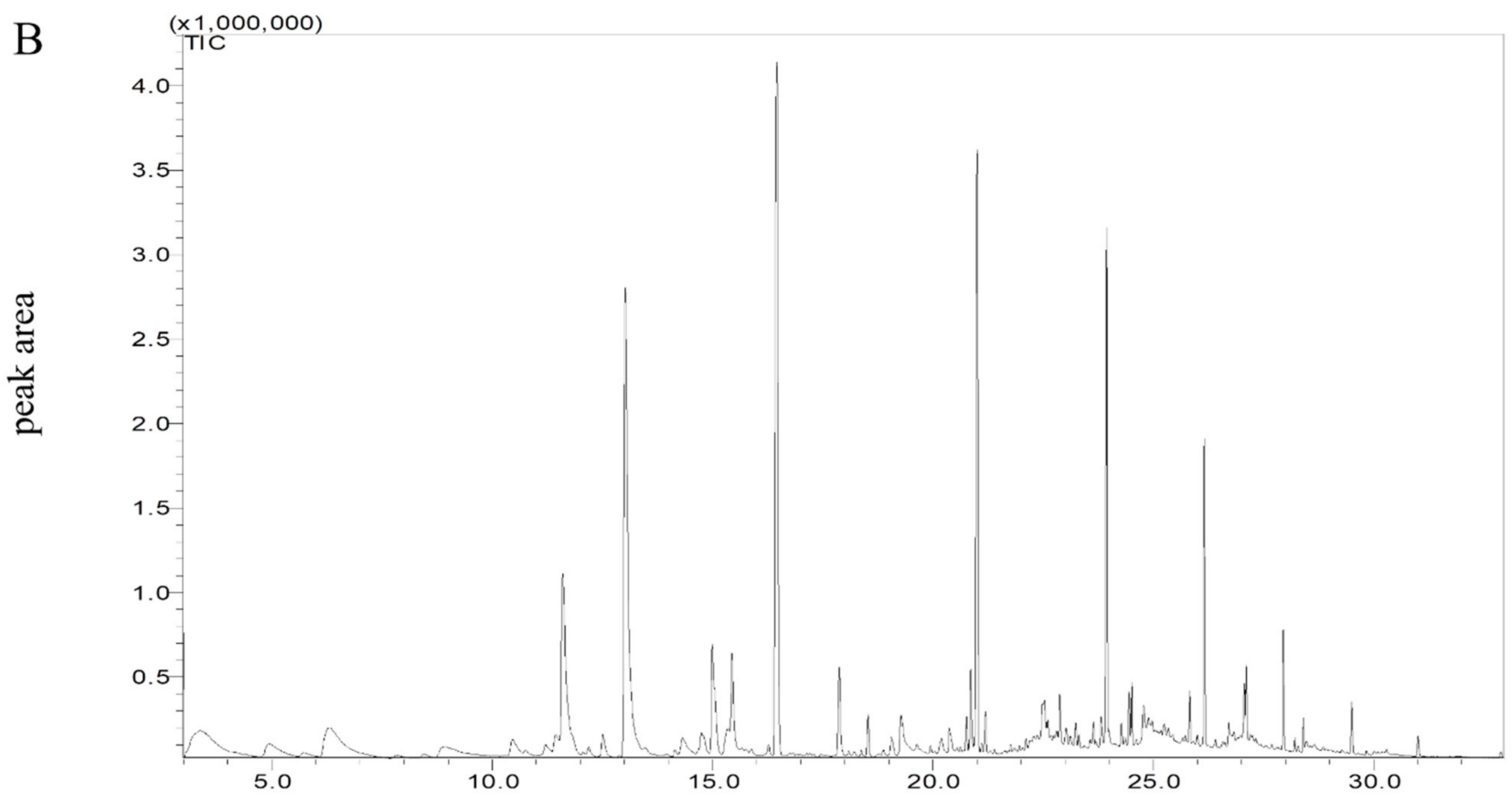

Time/min

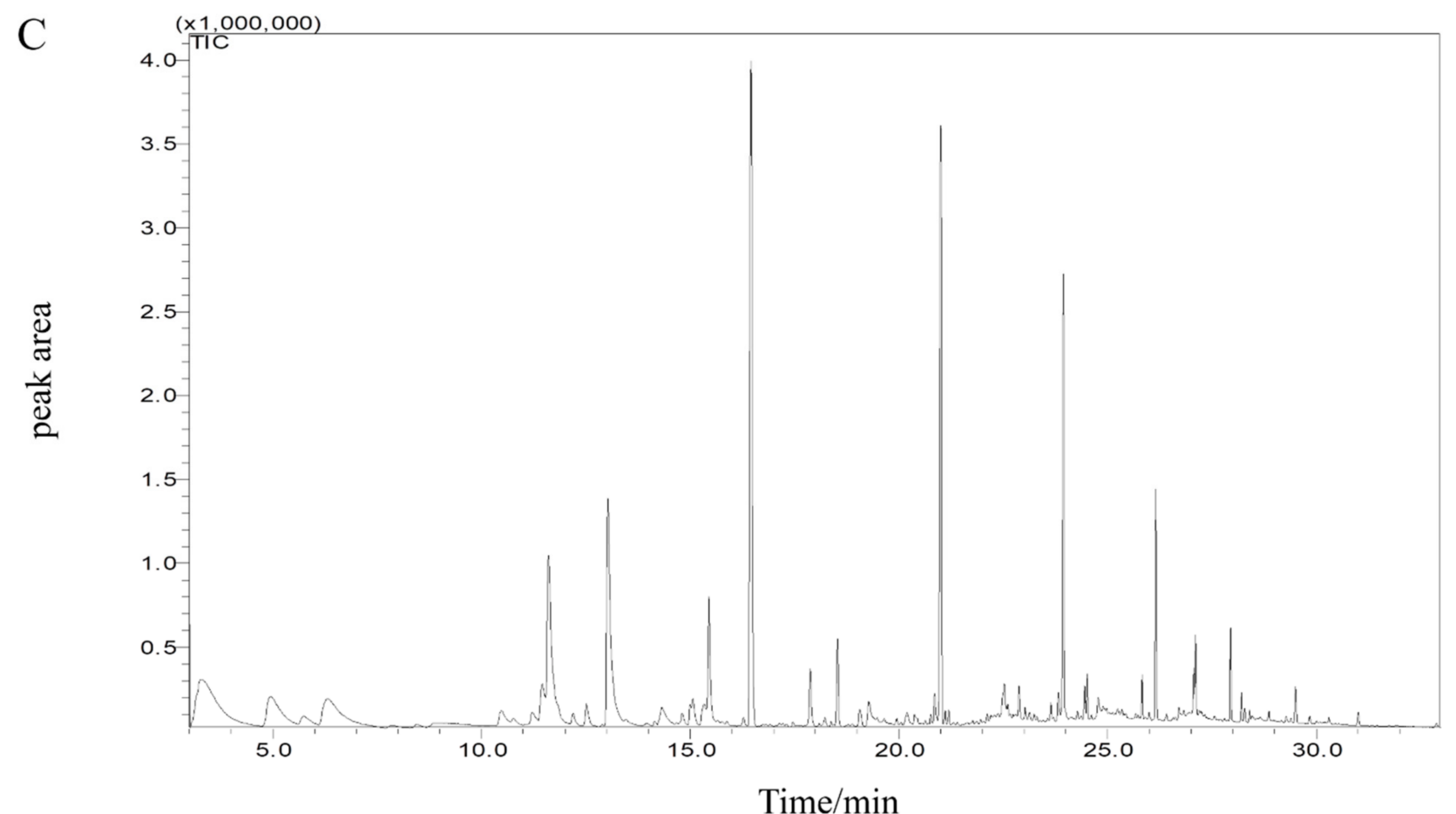

Figure 4. Cont. 


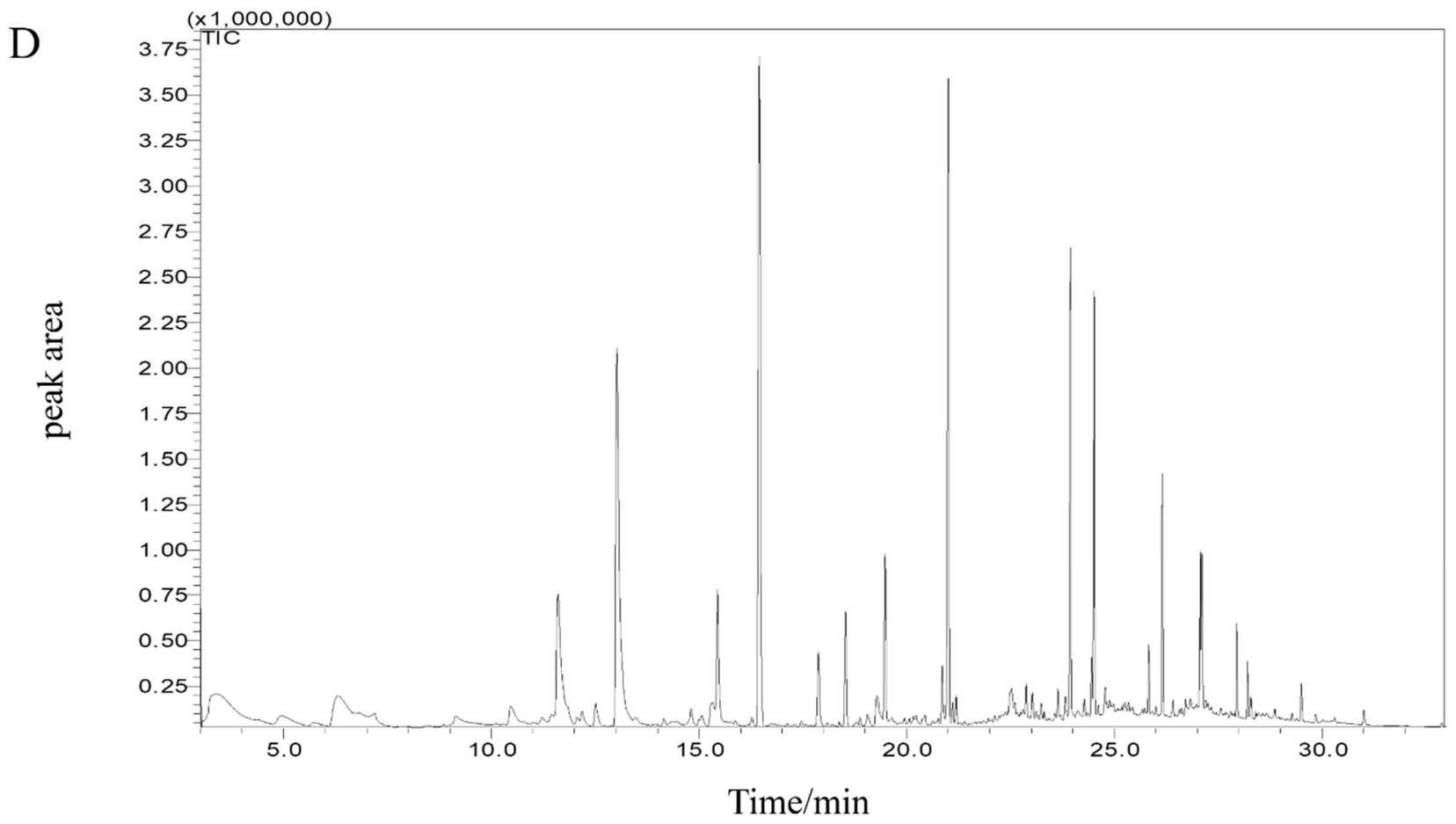

E

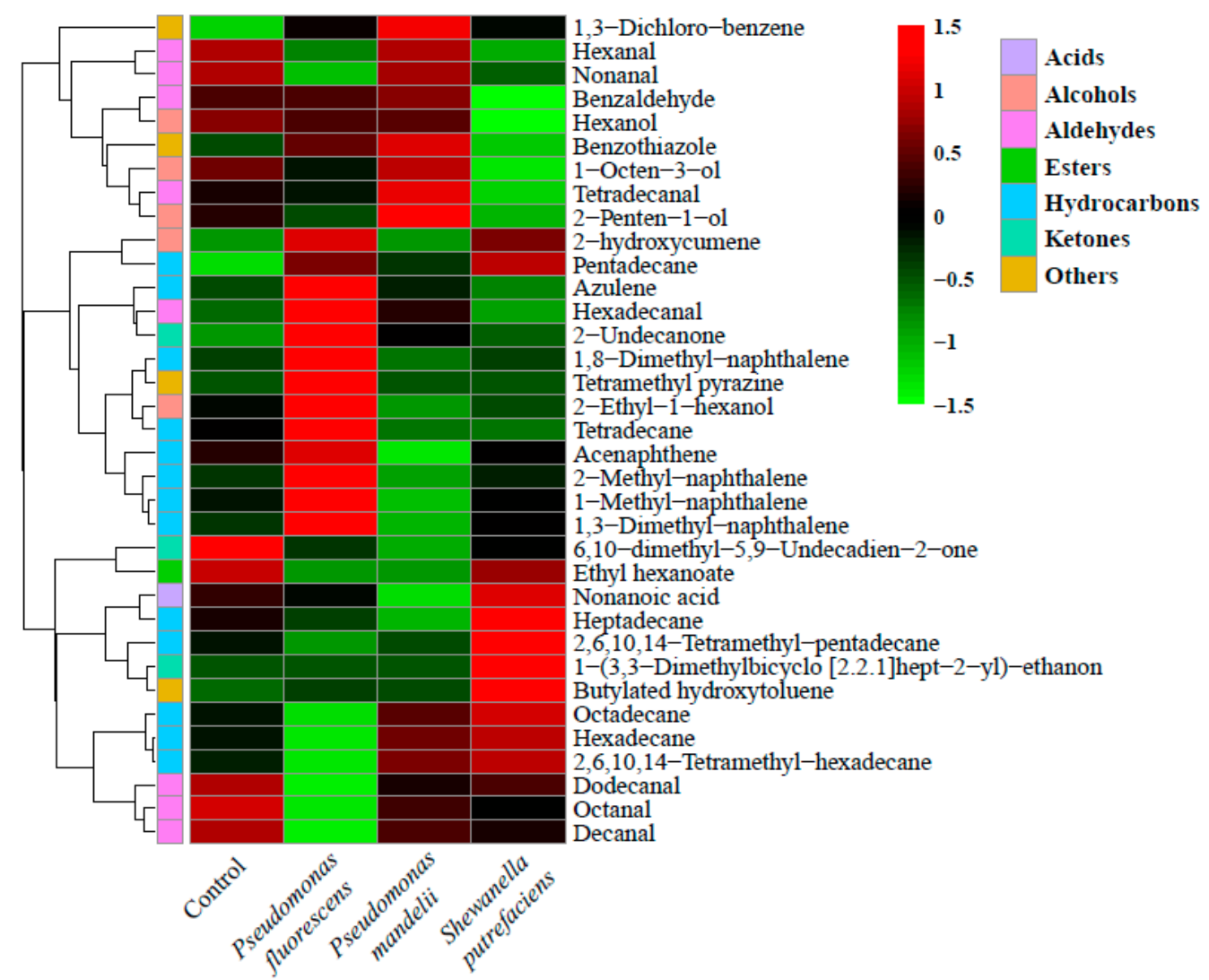

Figure 4. Total ion current diagram of volatile compounds and heat-map in sturgeon fillets inoculated with different bacteria stored aerobically on ice. Control (A); Pseudomonas fluorescens (B); Pseudomonas mandelii (C); Shewanella putrefaciens (D); heatmap (E). The level 3 pathways annotations were described on the left and colored according to level 2 categories. Acids, alcohols, aldehydes, esters, hydrocarbons, ketones, and other families were colored in violet, red, pink, green, blue, pistachio green, and yellow respectively. The hierarchical clustering tree was on left based on samples. 


\subsubsection{Principal Component Analysis (PCA)}

It should be noted that there may be some correlation between the changes of 35 volatile compounds detected. A certain overlap in the reflection of the odor characteristics of these volatile compounds should be considered. Therefore, PCA analysis was carried out to discover the correlation among aldehyde, ketone, acid, and other volatile compounds. The results showed three principal components were extracted, which could explain $47.98 \%, 35.41 \%$, and $16.62 \%$ of the total information respectively (Figure 5). The PC1 was mainly negatively correlated with most aldehydes (hexanal, octanal, nonanal, decanal); it was negatively correlated with hexadecaldehyde, 1-[3,3dimethylbicyclo [2.2.1] heptyl-2-yl] ethanone, octanol, 2-phenylisopropanol, osiridine, tetradecane, acenaphthene, tetramethylpyrazine, and all polycyclic aromatic hydrocarbons, octyl alcohol, 2-phenylisopropanol, osilane, and tetradecane. The second principal component mainly reacted with benzaldehyde, 1-[3,3-dimethylbicyclo [2.2.1] hept-2-yl] ethanone, nonanoic acid, 1-octen-3-ol, hexadecane, 2,6,10,14-tetramethylpentadecane, heptadecane, and di-tert-butyl-p-cresol. It can be seen from Figure 5B that the PC3 (16.62\%) mainly explains the changes of 1,3-Dichlorobenzene; 6,10-dimethyl-5,9-undecane-2-one, and hexanol. These substances may be the main contributors to the odor changes of sturgeon during storage.

(A)

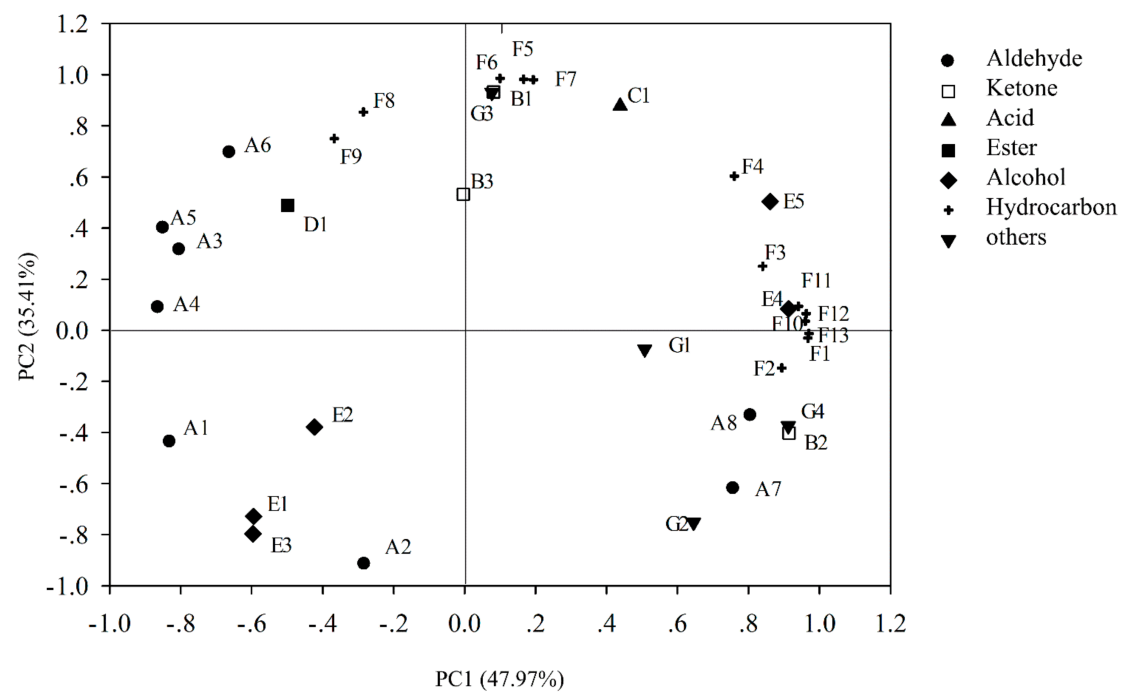

(B)

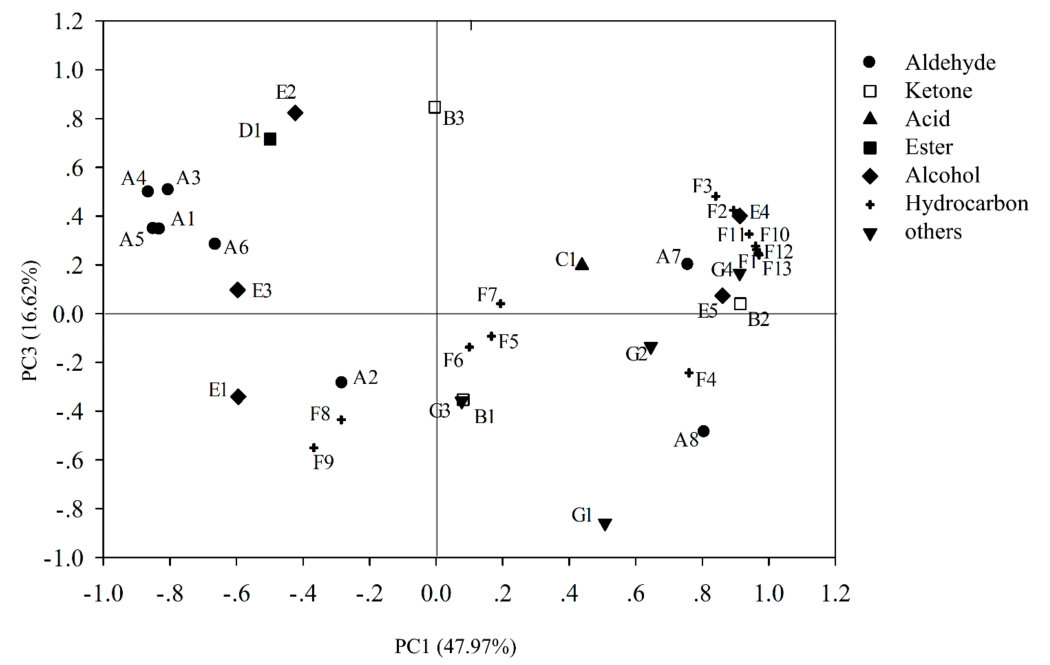

Figure 5. Variable loadings on plane1-2 (A) and 1-3 (B) of principle component analysis (PCA) on volatile compounds. 
On this basis, the principal component scores of each experimental group were calculated (Table 2). The results showed that in the Pseudomonas fluorescens group, the greatest contribution comes from PC1, which indicated that some related volatile compounds might be the main source of odor of spoilage fish treated by Pseudomonas fluorescens. The PC2 had the greatest effect on the putrefaciens of Shewanella putrefaciens group, and only changed significantly in the fish treated by Shewanella putrefaciens, which may be related to the putrefaction characteristics of Shewanella putrefaciens.

Table 2. Component scores on volatile compounds of sturgeon inoculated different SSOs, respectively.

\begin{tabular}{cccc}
\hline & $\begin{array}{c}\text { PC1 } \\
\mathbf{( 4 7 . 9 7 \% )}\end{array}$ & $\begin{array}{c}\text { PC2 } \\
\mathbf{( 3 5 . 4 1 \% )}\end{array}$ & $\begin{array}{c}\text { PC3 } \\
\mathbf{( 1 6 . 6 2 \% )}\end{array}$ \\
\hline $\begin{array}{c}\text { Control } \\
\text { Pseudomonas }\end{array}$ & -3.18 & 0.06 & 3.10 \\
fluorescens & 5.61 & -2.00 & 0.60 \\
Pseudomonas mandelii & -2.93 & -3.01 & -2.42 \\
Shewanella putrefaciens & 0.50 & 4.92 & -1.28 \\
\hline
\end{tabular}

\section{Conclusions}

Pseudomonas fluorescens, Pseudomonas mandelii, and Shewanella putrefaciens were strong spoilers on sturgeon fillets stored aerobically, by increasing TVBN content, fat oxidation degree and histamine content to stimulate fish spoilage. Different off-flavor characteristics of SSOs were performed. Pseudomonas fluorescens was correlated with the production of several polycyclic aromatic hydrocarbons and tetramethyl-pyrazine; 1-octen-3-ol and (z)2-penten-1-o can be proposed as the spoilage marker of sturgeon spoiled by Pseudomonas mandelii; 1-(3,3-dimethylbicyclo [2.2.1] hept-2-yl)-ethanon and ethyl hexanoate were the specific volatile compounds produced in sturgeon inoculated with Shewanella putrefaciens and can be used as a spoilage marker for Shewanella putrefaciensthus.

Supplementary Materials: The following are available online at https:/ /www.mdpi.com/article / 10.3390/foods10092021/s1, Table S1: Volatile compounds identified in tray-packaging sturgeon fillets inoculated different SSOs, respectively, stored for 15 days on ice.

Author Contributions: Methodology, Z.Z., R.W. and P.L.; formal analysis, M.G.; data curation, Z.J.; writing-original draft preparation, Z.Z. and R.W.; writing-review and editing, P.L. All authors have read and agreed to the published version of the manuscript.

Funding: This research was funded by Beijing Innovation Team of sturgeon and trout, grant number BAIC08-2021. The funders had no role in the study design, data collection and analysis, decision to publish, or preparation of the manuscript.

Acknowledgments: We gratefully acknowledge the Sturgeon Farm of Beijing Fisheries Research Institute, Beijing, China for providing the sturgeon materials for this study.

Conflicts of Interest: The authors declare no conflict of interest.

\section{References}

1. Food and Agriculture Organization (FAO). The State of World Fisheries and Aquaculture; FAO: Rome, Italy, 2020.

2. Wei, Q.W.; Zou, Y.; Li, P.; Li, L. Sturgeon aquaculture in China: Progress, strategies and prospects assessed on the basis of nation-wide surveys (2007-2009). J. Appl. Ichthyol. 2011, 27, 162-168. [CrossRef]

3. Cai, W.; Chen, Y.; Dong, X.; Shi, Y.; Wei, J.; Liu, F. Protein oxidation analysis based on comparative proteomic of Russian sturgeon (Acipenser gueldenstaedti) after sous-vide cooking. Food Control 2021, 121, 107594. [CrossRef]

4. Islam, M.R.; Yuhi, T.; Meng, D.; Yoshioka, T.; Ogata, Y.; Ura, K.; Takagi, Y. Purity and properties of gelatins extracted from the head tissue of the hybrid kalamtra sturgeon. LWT Food Sci. Technol. 2021, 142, 110944. [CrossRef]

5. Gui, M.; Wu, R.; Liu, L.; Wang, S.; Zhang, L.; Li, P. Effects of quorum quenching by AHL lactonase on AHLs, protease, motility and proteome patterns in Aeromonas veronii LP-11. Int. J. Food Microbiol. 2017, 252, 61-68. [CrossRef] [PubMed]

6. Dalgaard, P. Qualitative and quantitative characterization of spoilage bacteria from packed fish. Int. J. Food Microbiol. 1995, 26, 319-333. [CrossRef] 
7. Huang, Z.; Jia, S.; Zhang, L.; Liu, X.; Luo, Y. Inhibitory effects and membrane damage caused to fish spoilage bacteria by cinnamon bark (Cinnamomum tamala) oil. LWT Food Sci. Technol. 2019, 112, 108195. [CrossRef]

8. Wang, J.; Fang, J.; Wei, L.; Zhang, Y.; Deng, H.; Guo, Y.; Hu, C.; Meng, Y. Decrease of microbial community diversity, biogenic amines formation, and lipid oxidation by phloretin in Atlantic salmon fillets. LWT Food Sci. Technol. 2019, 101, 419-426. [CrossRef]

9. Wang, Y.; Wang, Y.; Chen, J.; Koseki, S.; Yang, Q.; Yu, H.; Fu, L. Screening and preservation application of quorum sensing inhibitors of Pseudomonas fluorescens and Shewanella baltica in seafood products. LWT Food Sci. Technol. 2021, 149, 111749. [CrossRef]

10. Cen, S.; Fang, Q.; Tong, L.; Yang, W.; Zhang, J.; Lou, Q.; Huang, T. Effects of chitosan-sodium alginate-nisin preservatives on the quality and spoilage microbiota of Penaeus vannamei shrimp during cold storage. Int. J. Food Microbiol. 2021, $349,109227$. [CrossRef]

11. Wong, W.W.; Greening, C.; Shelley, G.; Lappan, R.; Leung, P.M.; Kessler, A.; Winfrey, B.; Poh, S.C.; Cook, P. Effects of drift algae accumulation and nitrate loading on nitrogen cycling in a eutrophic coastal sediment. Sci. Total Environ. 2021, 790, 147749. [CrossRef]

12. Zhao, Y.; Qin, Z.; Huang, Z.; Bao, Z.; Luo, T.; Jin, Y. Effects of polyethylene microplastics on the microbiome and metabolism in larval zebrafish. Environ. Pollut. 2021, 282, 117039. [CrossRef]

13. Parlapani, F.F.; Michailidou, S.; Anagnostopoulos, D.A.; Koromilas, S.; Kios, K.; Pasentsis, K.; Psomopoulos, F.; Argiriou, A.; Haroutounian, S.A.; Boziaris, I.S. Bacterial communities and potential spoilage markers of whole blue crab (Callinectes sapidus) stored under commercial simulated conditions. Food Microbiol. 2019, 82, 325-333. [CrossRef]

14. Silbande, A.; Cornet, J.; Cardinal, M.; Chevalier, F.; Rochefort, K.; Smith-Ravin, J.; Adenet, S.; Leroi, F. Characterization of the spoilage potential of pure and mixed cultures of bacterial species isolated from tropical yellowfin tuna (Thunnus albacares). J. Appl. Microbiol. 2018, 124, 559-571. [CrossRef] [PubMed]

15. Odeyemi, O.A.; Burke, C.M.; Bolch, C.; Stanley, R. Evaluation of spoilage potential and volatile metabolites production by Shewanella baltica isolated from modified atmosphere packaged live mussels. Food Res. Int. 2018, 103, 415-425. [CrossRef] [PubMed]

16. Pedros-Garrido, S.; Clemente, I.; Calanche, J.B.; Condon-Abanto, S.; Beltran, J.A.; Lyng, J.G.; Brunton, N.; Bolton, D.; Whyte, P. Antimicrobial activity of natural compounds against listeria spp. and their effects on sensory attributes in salmon (Salmo salar) and cod (Gadus morhua). Food Control 2020, 107, 106768. [CrossRef]

17. Jia, S.; Huang, Z.; Lei, Y.; Zhang, L.; Li, Y.; Luo, Y. Application of Illumina-MiSeq high throughput sequencing and culturedependent techniques for the identification of microbiota of silver carp (Hypophthalmichthys molitrix) treated by tea polyphenols. Food Microbiol. 2018, 76, 52-61. [CrossRef]

18. Joffraud, J.J.; Cardinal, M.; Cornet, J.; Chasles, J.S.; Leon, S.; Gigout, F.; Leroi, F. Effect of bacterial interactions on the spoilage of cold-smoked salmon. Int. J. Food Microbiol. 2006, 112, 51-61. [CrossRef]

19. Hauschild, P.; Hilgarth, M.; Vogel, R.F. Hydrostatic pressure- and halotolerance of Photobacterium phosphoreum and P. carnosum isolated from spoiled meat and salmon. Food Microbiol. 2021, 99, 103679. [CrossRef]

20. Leroi, F.; Cornet, J.; Chevalier, F.; Cardinal, M.; Coeuret, G.; Chaillou, S.; Joffraud, J.J. Selection of bioprotective cultures for preventing cold-smoked salmon spoilage. Int. J. Food Microbiol. 2015, 213, 79-87. [CrossRef]

21. Schaffer, P.A.; Lifland, B.; Van Sommeran, S.; Casper, D.R.; Davis, C.R. Meningoencephalitis associated with Carnobacterium maltaromaticum-like bacteria in stranded juvenile salmon sharks (Lamna ditropis). Vet. Pathol. 2013, 50, 412-417. [CrossRef]

22. Wagner, E.M.; Fischel, K.; Rammer, N.; Beer, C.; Palmetzhofer, A.L.; Conrady, B.; Roch, F.; Hanson, B.T.; Wagner, M.; Rychli, K. Bacteria of eleven different species isolated from biofilms in a meat processing environment have diverse biofilm forming abilities. Int. J. Food Microbiol. 2021, 349, 109232. [CrossRef]

23. Turcihan, G.; Turgay, E.; Yardimci, R.E.; Eryalcin, K.M. The effect of feeding with different microalgae on survival, growth, and fatty acid composition of Artemia franciscana metanauplii and on predominant bacterial species of the rearing water. Aquacult. Int. 2021, 1-19. [CrossRef]

24. Miller, A.; Scanlan, R.; Lee, J.; Libbey, L. Volatile compounds produced in sterile fish muscle (Sebastes melanops) by Pse-domonas putrefaciens, Pseudomonas fluorescens, and an Achromobacter species. Appl. Microbiol. 1973, 26, 18-21. [CrossRef]

25. Wang, S.; He, J. Two-step denaturing gradient gel electrophoresis (2S-DGGE), a gel-based strategy to capture full-length 16S rRNA gene sequences. Appl. Microbiol. Biot. 2012, 95, 1305-1312. [CrossRef] [PubMed]

26. Huang, Z.; Liu, X.; Jia, S.; Zhang, L.; Luo, Y. The effect of essential oils on microbial composition and quality of grass carp (Ctenopharyngodon idellus) fillets during chilled storage. Int. J. Food Microbiol. 2018, 266, 52-59. [CrossRef] [PubMed]

27. Hovda, M.B.; Sivertsvik, M.; Lunestad, B.T.; Lorentzen, G.; Rosnes, J.T. Characterisation of the dominant bacterial population in modified atmosphere packaged farmed halibut (Hippoglossus hippoglossus) based on 16S rDNA-DGGE. Food Microbiol. 2007, 24, 362-371. [CrossRef] [PubMed]

28. Botsoglou, N.; Fletouris, D.; Papageorgiou, G.; Vassilopoulos, V.; Mantis, A.; Trakatellis, A. Rapid, sensitive, and specific thiobarbituric acid method for measuring lipid peroxidation in animal tissue, food, and feedstuff samples. J. Agric. Food Chem. 1994, 42, 1931-1937. [CrossRef]

29. Broekaert, K.; Heyndrickx, M.; Herman, L.; Devlieghere, F.; Vlaemynck, G. Seafood quality analysis: Molecular identification of dominant microbiota after ice storage on several general growth media. Food Microbiol. 2011, 28, 1162-1169. [CrossRef] [PubMed] 
30. Li, T.; Li, J.; Hu, W. Changes in microbiological, physicochemical and muscle proteins of post mortem large yellow croaker (Pseudosciaena crocea). Food Control 2013, 34, 514-520. [CrossRef]

31. Liu, D.; Liang, L.; Xia, W.; Regenstein, J.M.; Zhou, P. Biochemical and physical changes of grass carp (Ctenopharyngodon idella) fillets stored at -3 and $0{ }^{\circ} \mathrm{C}$. Food Chem. 2013, 140, 105-114. [CrossRef]

32. Dabade, D.S.; Azokpota, P.; Nout, M.J.R.; Hounhouigan, D.J.; Zwietering, M.H.; den Besten, H.M.W. Prediction of spoilage of tropical shrimp (Penaeus notialis) under dynamic temperature regimes. Int. J. Food Microbiol. 2015, 210, 121-130. [CrossRef] [PubMed]

33. Reynisson, E.; Lauzon, H.L.; Magnusson, H.; Jonsdottir, R.; Olafsdottir, G.; Marteinsson, V.; Hreggviosson, G.O. Bacterial composition and succession during storage of North-Atlantic cod (Gadus morhua) at superchilled temperatures. BMC Microbiol. 2009, 9, 250. [CrossRef] [PubMed]

34. Li, Q.; Zhang, L.; Luo, Y. Changes in microbial communities and quality attributes of white muscle and dark muscle from common carp (Cyprinus carpio) during chilled and freeze-chilled storage. Food Microbiol. 2018, 73, 237-244. [CrossRef] [PubMed]

35. Mondal, S.; Pramanik, K.; Ghosh, S.K.; Pal, P.; Mondal, T.; Soren, T.; Maiti, T.K. Unraveling the role of plant growth-promoting rhizobacteria in the alleviation of arsenic phytotoxicity: A review. Microbiol. Res. 2021, 250, 126809. [CrossRef]

36. Liu, X.; Huang, Z.; Jia, S.; Zhang, J.; Li, K.; Luo, Y. The roles of bacteria in the biochemical changes of chill-stored bighead carp (Aristichthys nobilis): Proteins degradation, biogenic amines accumulation, volatiles production, and nucleotides catabolism. Food Chem. 2018, 255, 174-181. [CrossRef]

37. Hernandez, M.D.; Lopez, M.B.; Alvarez, A.; Ferrandini, E.; Garcia, B.G.; Garrido, M.D. Sensory, physical, chemical and microbiological changes in aquacultured meagre (Argyrosomus regius) fillets during ice storage. Food Chem. 2009, 114, 237-245. [CrossRef]

38. Zhang, Q.; Chen, X.; Ding, Y.; Ke, Z.; Zhou, X.; Zhang, J. Diversity and succession of the microbial community and its correlation with lipid oxidation in dry-cured black carp (Mylopharyngodon piceus) during storage. Food Microbiol. 2021, 98, 103686. [CrossRef]

39. Nychas, G.; Dillon, V.; Board, R. Glucose, the key substrate in the microbiological changes occurring in meat and certain meat products. Biotechnol. Appl. Bioc. 1988, 10, 203-231.

40. Saenz-Garcia, C.E.; Castaneda-Serrano, P.; Silva, E.M.M.; Alvarado, C.Z.; Nava, G.M. Insights into the Identification of the Specific Spoilage Organisms in Chicken Meat. Foods 2020, 9, 225. [CrossRef] [PubMed]

41. Doulgeraki, A.I.; Ercolini, D.; Villani, F.; Nychas, G.E. Spoilage microbiota associated to the storage of raw meat in different conditions. Int. J. Food Microbiol. 2012, 157, 130-141. [CrossRef]

42. Liu, C.; Li, W.; Lin, B.; Yi, S.; Ye, B.; Mi, H.; Li, J.; Wang, J.; Li, X. Effects of ozone water rinsing on protein oxidation, color, and aroma characteristics of grass carp (Ctenopharyngodon idellus) surimi. J. Food Process. Pres. 2021, e15811. [CrossRef]

43. Mace, S.; Joffraud, J.; Cardinal, M.; Malcheva, M.; Cornet, J.; Lalanne, V.; Chevalier, F.; Serot, T.; Pilet, M.; Dousset, X. Evaluation of the spoilage potential of bacteria isolated from spoiled raw salmon (Salmo salar) fillets stored under modified atmosphere packaging. Int. J. Food Microbiol. 2013, 160, 227-238. [CrossRef] [PubMed]

44. Selli, S.; Cayhan, G.G. Analysis of volatile compounds of wild gilthead sea bream (Sparus aurata) by simultaneous distillationextraction (SDE) and GC-MS. Microchem. J. 2009, 93, 232-235. [CrossRef]

45. Iglesias, J.; Medina, I.; Bianchi, F.; Careri, M.; Mangia, A.; Musci, M. Study of the volatile compounds useful for the characterisation of fresh and frozen-thawed cultured gilthead sea bream fish by solid-phase microextraction gas chromatography-mass spectrometry. Food Chem. 2009, 115, 1473-1478. [CrossRef]

46. Zhang, Z.; Li, G.; Luo, L.; Chen, G. Study on seafood volatile profile characteristics during storage and its potential use for freshness evaluation by headspace solid phase microextraction coupled with gas chromatography-mass spectrometry. Anal. Chim. Acta 2010, 659, 151-158. [CrossRef] 